fatality rates with the overall increase in the number of vehicles adjusted by population during the study period.

Results The information sources differ as far as percentages were concerned $(1.3 \%-6.5 \%)$, but they coincided in the fact that fatalities increased by around $40 \%$ (2014). 37\% of the fatalities occurred in three provincial departments: Antioquia (14.4\%), Valle (12.5\%) and Bogotá (10.1\%). The average fatality rate for 2014 was nearly 14.0/100,000 inhabitants; although it was higher in the provincial departments of Casanare (37.7), Arauca (27.9), Meta (26.6), and Cesar (25.7). There was a positive correlation between TIFs and the increase in the number of vehicles in Colombia ( $\mathrm{p}<0.001)$.

Conclusions Road safety management in Colombia is restricted due to the lack of a leading agency to direct, control, and manage policies. Although a decree to create a National Road Safety Agency was issued in 2013, the year 2015 is now closing and such agency has not initiated operations. Poor implementation and non-compliance with traffic laws and regulations seem to be the main cause for traffic accidents.

\section{GLOBAL ALLIANCE OF NGOS FOR ROAD SAFETY}

Lotte Brondum. Global Alliance of NGOs for Road Safety

\subsection{6/injuryprev-2016-042156.535}

Background Road traffic crashes and resultant injuries and fatalities have become a major global problem as countries develop and rapidly acquire motorised vehicles. The United Nations launched the UN Decade of Action for Road Safety 2011-2020 to coordinate global efforts and promote solutions to this increasing health issue. The Global Alliance of NGOs for Road Safety was established in response to the Decade of Action, and provides a forum for non-governmental organisations to share best practices and collectively advocate for road safety and the rights of victims of traffic crashes. The Alliance currently represents more than 140 NGOs from over 70 countries.

Problem Each year, more than 1.2 million people die on the world's roads and tens of millions are seriously injured. Traffic crashes are currently the number one killer of young people aged 14-29, and the eighth leading cause of death among all people worldwide. Alongside the devastation that traffic crashes impose on victims' families and loved ones, traffic crashes take a tremendous toll on the economy. Each year, developing countries lose between $1 \%$ and $3 \%$ of their GDP as a result of traffic crashes. Thankfully, these consequences are preventable and NGOs play a critical role in reducing the impact of traffic crashes in their communities and around the world.

Solution The Global Alliance of NGOs for Road Safety serves as a platform for NGOs to share best practices and coordinate efforts to implement effective road safety programs and campaigns. The Alliance provides services and support to its members in three key areas: 1) networking and sharing, 2) advocacy, and 3) capacity building and training. The Alliance also provides information about the activities of NGOs to non-NGO actors, such as governments, multilateral organisations, media, and other stakeholders to promote road safety in the global development agenda. The Alliance consistently reaches more than 140 member NGOs and more than 600 other road safety advocates through official communication platforms, organised conferences, and other outreach efforts and services.

Conclusions The Global Alliance of NGOs for Road Safety is an effective platform for NGOs working in road safety to share ideas, best practices, and coordinate international campaigns to promote road safety and the right's of road victims in their countries and around the world.

\section{FEDEX GLOBAL ROAD SAFETY TRAINING PROGRAM}

${ }^{1}$ Lotte Brondum, ${ }^{2}$ Shane O'Connor. ${ }^{1}$ Global Alliance of NGOs for Road Safety; ${ }^{2}$ FedEx

10.1136/injuryprev-2016-042156.536

Background Each year, more than 1.2 million people die on the world's roads and tens of millions are seriously injured. Traffic crashes are currently the number one killer of young people aged 14-29, and the eighth leading cause of death among all people worldwide. However, these devastating consequences are preventable, and NGOs play a critical role in reducing the impact of traffic crashes in their communities and around the world. However, many NGOs still struggle to reach their full impact due to a lacking of training and expertise in critical operational areas including project management, fundraising, etc.

Objective To improve NGO capacity to implement effective road safety programs, FedEx and the Global Alliance of NGOs for Road Safety, which represents more than 140 NGOs from over 70 countries, have partnered to develop a targeted training program for road safety NGOs. The FedEx Global Road Safety Training Program focuses on key areas for programatic improvement including: project management; fundraising and proposal writing; research, monitoring and evaluation; communications; and more. Specifically, the Training Program includes face-to-face training workshops conducted in key regions of the world, as well the development of public webinars, online tool-kits, and mentor programs for NGOs. This program is expected to improve NGOs' ability to design and implement effective programs to advocate for road safety and reduce traffic-related injuries and fatalities in their localities.

Results Currently, the Alliance is conducting a needs assessment among member NGOs to gather information on area-specific weaknesses of members, to inform the specific content of the Training Program. The Training Program will formally launch at the $2^{\text {nd }}$ High-Level Conference on Road Safety in Brazil on 1819 November 2015. The Training Program will be systematically monitored and evaluated to determine the effectiveness of the Training Program in improving member NGOs capacity to design and implement road safety programs with measurable results.

Conclusions NGOs have significant potential to reduce trafficrelated injuries and fatalities and advocate for road safety by implementing community programs, but many NGOs lack training in key operational areas to ensure the effectiveness of their programs. The FedEx Global Road Safety Training Program will provide this training to road safety NGOs around the world.

\section{CONSENSUS DRIVEN DESIGN OF CHILD RESTRAINT PRODUCT INFORMATION TO REDUCE MISUSE}

${ }^{1}$ Alexandra Hall, ${ }^{1}$ Catherine Ho, ${ }^{2}$ Lisa Keay, ${ }^{3}$ Kirsten McCaffery, ${ }^{2}$ Kate Hunter, ${ }^{4}$ Judith Charlton, ${ }^{1}$ Lynne Bilston, ${ }^{5}$ Andrew Hayen, ${ }^{1}$ Julie Brown. ${ }^{1}$ Neuroscience Research Australia, the University of New South Wales, Sydney, NSW, Australia; ${ }^{2}$ the George Institute for Global Health, the University of Sydney, Sydney, NSW, Australia; ${ }^{3}$ the University of Sydney, Sydney, NSW, Australia; ${ }^{4}$ Monash University, Victoria, Australia, ${ }^{5}$ the University of New South Wales, Sydney, NSW

10.1136/injuryprev-2016-042156.537 